\title{
Escaping the Climate Trap: Participation in a Climate-Specific Social Dilemma Simulation Boosts Climate-Protective Motivation and Actions
}

\author{
Perri B. Druen ${ }^{1, *(\mathbb{D})}$ and Stephanie J. Zawadzki ${ }^{2}$ \\ 1 Department of Psychology, York College of Pennsylvania, York, PA 17403, USA \\ 2 Environmental Psychology, University of Groningen, 9712 TS Groningen, The Netherlands; \\ s.johnson.zawadzki@rug.nl \\ * Correspondence: pdruen@ycp.edu; Tel.: +1-717-815-1768
}

Citation: Druen, P.B.; Zawadzki, S.J. Escaping the Climate Trap:

Participation in a Climate-Specific Social Dilemma Simulation Boosts Climate-Protective Motivation and Actions. Sustainability 2021, 13, 9438. https://doi.org/ 10.3390/su13169438

Academic Editor:

Mohammad Valipour

Received: 1 July 2021

Accepted: 18 August 2021

Published: 23 August 2021

Publisher's Note: MDPI stays neutral with regard to jurisdictional claims in published maps and institutional affiliations.

\begin{abstract}
One way in which educators can help to address increasingly pressing environmental problems, including climate change, is to encourage individuals to change their behavior and to press for structural changes in society. The promotion of climate-protective behavior is challenging because the payoffs for various actions and inactions are structured such that they create social dilemmas. The conflict between short-term personal benefit and long-term collective gain in such dilemmas often leads to self-serving motives that can ultimately be self-defeating. We created a social dilemma simulation specific to climate change, called Climate Trap: Social Dilemma Simulation, to help students observe how they and others respond to these conflicts, and predicted that doing so would lead to climate-protective motivations and behaviors after the simulation. The simulation participants $(\mathrm{N}=344)$ reported greater confidence in their knowledge and understanding of the social dilemma context of climate change, higher environmental concern and more self-determined motivation to act, and they engaged in more climate-protective behaviors compared to the students who did not complete the simulation. Moreover, the simulation participants reported greater pro-environmental engagement on all of the measures after the simulation compared to before they participated in the simulation. The results suggest that a climate-specific social dilemma simulation can create uniquely motivating experiences, and can have utility as a teaching tool, research instrument and intervention.
\end{abstract}

Keywords: social dilemma; climate change; intervention; human behavior; simulation; gaming

\section{Introduction}

Fully addressing climate change requires a system-wide set of adjustments including top-down, bottom-up and side-to-side changes. The need for revised policies and incentives, technological innovations, international cooperation and many other things is clear [1]. Although it has not yet risen to the necessary levels, individual behavior change is one important-albeit not solely sufficient-component in the array of solutions [2,3]. Actions that people can take within the scope of their everyday lives may provide a "behavioral wedge" to swiftly reduce carbon emissions, partly because they can be implemented immediately, partly because these behaviors account for a sizeable portion of carbon emissions $[4,5]$, and partly because individuals can push for larger social change. Education has a crucial role to play in helping people see their own contributions to the problems and to the solutions [6,7]. Environmental education has long been focused on providing opportunities for students to grow in their understanding of the natural world, with the intention of fostering greater care and eco-friendly behavior [8,9]. However, simply communicating that there is an environmental threat is usually not enough to influence behavior, despite increasing knowledge [10]; directly asking people to make changes is not much better [11]. This may be the case even among people who express care about the environment [12]. Therefore, other approaches that consider psychological factors must also be developed $[2,4]$. 
The climate change literacy movement has begun to include social and behavioral sciences [13]. Climate change as an environmental problem poses some unique challenges that further complicate attempts to guide behavior change. First, climate change cannot be perceived through human perceptual registers [14]. Unlike issues such as pollution, strip-mining, or forest clear-cutting, there is nothing to see in-person with climate change. This fact adds to the second challenge, which is that it is difficult for people to see how their own behavior contributes to climate change [15]. It is easy, for example, to see that throwing garbage in a lake contributes to pollution, but the link between consumer behavior and climate change is more difficult to perceive. Third, the behavior changes which are necessary to mitigate dangerous global warming effects are great in number and complexity, and often need to be repeated many times or across many situations. Despite the positive psychological effects that pro-environmental behaviors may offer people, like a sense of personal meaning [16] or enhanced subjective wellbeing [17], if people perceive climate-friendly behaviors as costly, inconvenient, or difficult to perform, they may be less inclined to act in a climate-friendly manner.

In order to address these particular challenges, educational interventions that can model climate-change-relevant behavior are needed, so that people can understand how human behavior contributes to global warming processes. In addition, the interventions must be engaging and powerful enough to overcome resistance to change so that they can promote climate-protective actions. Thus, educators should design interventions that target climate behaviors' deeper underlying drivers, like climate change beliefs [18], environmental concern [19], pro-environmental values and respect for nature [20], and the motivation to act in a climate-protective manner [21]. In addition to tapping into behavioral antecedents, effective climate-change-relevant behavior interventions should also help people see the link between their own behavior and climate change. Personal experiences strengthen attitudes and are more likely to produce the associated behavior change [22]. For the field of education to realize its potential to be a force for the promotion of the critical changes needed to protect the Earth from becoming an uninhabitably warm planet, it will be particularly important to develop such strong experiential educational designs. Simulations, particularly those that demonstrate climate change in the context of individual behavior, can be valuable in meeting this challenge because they create highly engaging educational experiences which can be tailored to many topics, like how people's behaviors contribute to climate change.

Behavior that drives global warming results in part from a social-psychological phenomenon known as a social dilemma [23-25]. A social dilemma is a situation in which there is an inherent conflict between people's short- and long-term interest, and between their own personal benefit versus communal benefit. In general, people tend to make decisions favoring their own comfort or profit in the immediate term. For example, unnecessary emissions of greenhouse gasses occur when corporations produce consumer goods using fossil fuel inputs, and people do not take the extra time to seek out sustainably produced goods which could be more expensive. These decisions take place in a matrix of options that make the climate-damaging action the easiest or most profitable decision. However, in the long-term, these fossil fuel emissions contribute to a progressively unstable and dangerous warming of the planet. Social dilemmas powerfully influence decision-making, but they are difficult to notice, and it can be so hard to break free from their influence that they are often referred to in the literature as 'traps'. Many studies have shown how otherwise-rational short-term self-interest can lead to the irrational outcome of self- and collective-detriment over time-which, with respect to climate change specifically, threatens human survival. Importantly, the construct of a social dilemma captures how individual decisions are constrained by the more structural and macro-forces in play. Understanding how these constraints are woven into societal institutions, policies and cultural expectations, both incidentally and purposefully [26,27], can highlight the need for change at multiple levels.

Moreover, people have a particularly difficult time predicting how they would behave under the pressures of social dilemmas' unique tradeoffs [24]. They regularly discount 
how situational factors, such as the features of a social dilemma, would affect them and others [28]. Such discounting leads to attributions in which they over-blame others whose actions cause harm, but excuse themselves; otherwise, they falsely believe that they themselves would be willing to make sacrifices that others would not. In addition, people tend to expect that solving environmental problems is up to others, such as governments or corporations $[29,30]$. Despite attributing agency to others, they often perceive themselves as having low efficacy for contributing solutions to a problem as daunting as climate change [31]. Learning more about how systems and decisions interact would help people see all of the roles and responsibilities that are distributed across the causes of climate change and the responsibilities for mitigation. As such, they would be in better positions to take responsibility for their own contributions, as well as to advocate and demand change of other entities, including governments and corporations.

Thus, we aimed to create a teaching tool that would help people overcome their limited view of their and others' roles and responsibilities regarding climate change. We developed a simulation of the social dilemma of climate change, called Climate Trap: Social Dilemma Simulation, which was designed for people to gain insight into the dilemma tradeoffs, to observe how they themselves behave under the pressures, and to help them feel empowered to overcome short-term decisional traps that sacrifice the collective. We built upon previous research which suggested that when people have a better understanding of why they and others typically opt for short-term personal benefits instead of the long-term collective benefits, they are better at recognizing how their own individual behavior contributes to collective problems [24]. We predicted that this change in understanding would motivate people to engage with climate change mitigation because they feel personally responsible to act, and to push others to do their part. Therefore, the purpose of this paper is twofold. First, we aimed to determine whether participating in a social dilemma simulation about climate change would help people understand that because individual decisions contribute to collective problems, individual decisions could contribute to the collective solutions. Our second goal was to determine if the simulation could, in turn, increase concern about and belief in climate change, as well as promoting motivation and actual behavior to address it.

\subsection{Climate Change as a Social Dilemma}

Environmental problems [32], and specifically global climate change, are increasingly understood as super-wicked $[33,34]$ collective action problems resulting from decisions made by individuals, corporations and governments in the context of large-scale social dilemma pressures [35-39]. Raihani and Aitken went so far as to suggest that "climate change represents the largest social dilemma humans have ever faced" [40], (p. 47). Climate change has elements of three types of traps: social (self vs. collective), temporal (immediate vs. delayed consequences) and spatial (here vs. somewhere else) [41]. One way to operationalize this dilemma is as a resource commons dilemma in which there is a public good, in this case a stable climate, that can be maintained only when there are sufficient behaviors that refrain from, or reduce, greenhouse gas emissions. A related method is to consider it a collective risk dilemma in which reaching a collective target, such as reduced greenhouse gas emissions, requires individual sacrifice [42]. In such dilemmas, when they have the freedom to choose, it is typical for people to avoid sacrifice even when they would personally benefit in the long-term. It can be difficult to estimate the positive consequences to the self of favoring the collective (social discounting) and the future (temporal discounting), even when those consequences would be highly desirable, such as enhanced subjective well-being and life-satisfaction [17], reduced eco-anger or feelings of threat [43,44], or monetary benefits from existing financial incentives [45].

\subsection{Individual Decision-Making within Social Dilemmas}

In the context of civil freedom and the absence of laws that regulate all relevant behavior, an important piece of the multi-faceted set of solutions to climate change is to find ways to help individuals-including government and corporate leaders-to overcome 
their tendencies to make decisions that favor their own short-term self-interest over the future common good. There have been decades of research on factors that affect the decisions people make while facing tradeoffs within a social dilemma, e.g., $[24,35,41,46,47]$, but most of this research does not examine how the participants think about the dilemma itself. Whilst people may understand that climate change results from social dilemma pressures [35], this does not necessarily mean that they understand how a social dilemma affects their own decisions. In fact, Capstick suggested:

What is missing from the literature ... is a systematic attempt to understand the ways in which individuals themselves understand and reason about climate change as a social dilemma. This is important because ultimately it will be people's perceptions of the climate dilemma which will influence their responses to it. [35], (p. 3485)

There have been a few studies on the motivational effects of learning about social dilemmas and climate change, but the existing literature is mixed as to whether understanding climate change as a social dilemma would increase or decrease the motivation and willingness to act in a climate-protective manner. For example, Aitken and colleagues found that perceiving a social dilemma may limit the willingness to act to mitigate climate change [48]. This reaction can rest in assumptions or beliefs about fairness. People may believe that they will be exploited by contributing when others do not [49], or may believe that the outcome cannot be reached because others will not do their fair share [50]. Conversely, people who understand climate change as a social dilemma may begin to see the importance of their role in a larger problem, and may adjust their behavior accordingly. For example, Capstick found that some people tended to acknowledge that they had individual responsibility for action even if others were not willing to do so [35]. After participants understood that the true nature of social dilemmas includes decision-making tradeoffs, the participants expressed feeling compelled to do better and break free of the climate trap. This may have resulted from basing decisions on a new foundation, which pulled them away from more selfish motivations and toward more altruistic ones.

Importantly, we extend the existing literature by examining what happens when people not only learn about climate change as a social dilemma, but actively experience it themselves, and are able to observe and reflect on their own and others' behavior when caught in a trap. Specifically, we examined the extent to which a person's observation of their own or others' decisions in a social dilemma simulation can subsequently affect their behavior when confronted with related actual dilemma pressures in their own life. We expected that participation in our Climate Trap simulation, regardless of whether participants were cooperative within the simulation itself, could still change how they make decisions about their own real-world behavior choices. In this way, we were not using a simulation as they have been implemented previously (i.e., to assess factors that affect whether a participant is cooperative within the simulation). Instead, we were interested in affecting the participant's climate-related thinking, motivation and behavior after the simulation.

Protection Motivation Theory $[51,52]$ may help to explain why people may change after participation in our simulation. This theory of behavior change suggests that people change when they: (1) believe a threat to be severe (severity), (2) believe they are personally vulnerable to the negative outcomes (vulnerability), (3) believe there are actions that can mitigate the threat (response-efficacy), (4) feel capable of performing those actions (selfefficacy), and (5) feel the costs of action are not too large. This model can be applied to climate change in order to understand which kinds of interventions and appeals are more likely to be successful [53]. We expected the simulation to address all of these requisite elements, either directly or indirectly. People who participate in a climate change-specific social dilemma simulation should perceive climate change as a greater threat (i.e., severity) because they will recognize that it is very difficult to escape the trap of a social dilemma given the situational constraints. They may experience an increased sense of vulnerability because they will see the negative impacts of climate change as the commons quickly becomes depleted and the simulation ends. Then, because they see how behavior is affected 
by the specific payoffs structured into the simulation, and see that there could be alternative rules sets, such as taxing big emitters or rewarding cooperation over competition, they should also feel there are effective and workable solutions (i.e., response-efficacy). When they consider how they personally would act and make decisions in their own everyday lives, we expected that they would recognize that individual behavior indeed impacts changes to the climate, and therefore that behavior can be modified to mitigate the problems (i.e., self-efficacy). Finally, these changed perceptions should then boost the motivation to act to in a preventative/protective manner, and so they do what they can to act when they are given the opportunity after the simulation (the behavioral options we offered were designed to be ones the participants could easily do-i.e., the costs are low).

In sum, because climate change is a social dilemma, it typically influences people's decision-making to favor sort-term personal gain over long-term collective interests. We expected that participating in a climate-change-specific social dilemma simulation would offer participants a means of seeing how their individual behavior can influence collective outcomes, thereby motivating them to act in a more climate-protective manner and to push others to do the same.

\subsection{Description of "Climate Trap: Social Dilemma Simulation", Our Climate-Change-Specific Simulation}

Some researchers have argued that simulations and gaming provide an excellent educational methodology for learning about the complexities of climate change [54-57]. Indeed, a variety of climate-change games have been developed [56,57], many of which include modeling the changes to the climate so that participants learn how greenhouse gasses and other phenomena are related to climate problems. A few simulations specifically focus on the social dilemma aspects of climate change. For example, Milinski and colleagues [58] and Tavoni's research team [59] asked their participants to invest in an account that represented the climate, at the expense of their own personal account, and generally found that the participants were resistant to doing so.

We designed Climate Trap to explicitly tie individual decisions to changes in the climate. In most simulations, the target behavior and the outcome are on the same dimension (e.g., individuals catching fish with the outcome being the loss of fisheries, or over-grazing livestock with the outcome of less fertile grazing land). However, in Climate Trap, we wanted to show how behavior in one domain could affect outcomes in another domain. In this case, we tied decisions regarding the production of consumer goods to the higherorder issue of climate change. We intended that participants should see how individual decisions regarding something not specifically about the climate (e.g., the production of goods in a competitive marketplace) could, nevertheless, result in undesirable outcomes for the climate. The simulation was designed such that pursuing self-interest contributed to long-term climate collapse, which could ultimately harm the self (i.e., a temporal trap). In addition, pursuing self-interest would lead to a disadvantage for others (i.e., a social trap). We chose not to ask the participants to act as themselves making decisions about their own everyday behavior for several reasons, e.g., to add sufficient psychological distance between their behavior in the simulation and their behavior outside the simulation in order to avoid psychological reactance [60] on their part, which may have inhibited authentic responses. This layer of buffering is similar to Schwartz's commonly employed method of using third-person portraits to authentically assess socially loaded constructs like personal values and life goals [61]. We also wanted the participants to be able to see how more powerful others, in this case corporate heads, could be affected by social dilemma pressures, thereby helping people see that it is the system of payoffs and tradeoffs in the real world that need to be changed. Finally, we wanted to explicitly model the complexities in how multiple linked decisions can lead to climate change; specifically, that a corporate decision to make more products for consumers in the conduct of their normal business could ultimately harm the climate. We expected that participants would be able to infer that their own role as consumers in their real lives affects this process. 
In creating Climate Trap, we followed the recommendations of Williams and Williams, who proposed that simulations or games can change participants' attitudes most when those simulations engage participants in three areas: emotional identification (being personally invested), cognitive identification (seeing the simulation as a good analogue to real-world situations), and behavioral identification (developing their own strategies) [62]. For the purposes of student learning, we focused intently on making the simulation feel like it was very close to what people would experience in a real-world situation. Thus, we sought to increase the participants' cognitive identification by including important variables linked to climate change, and to appropriately represent their complex interrelationships. In our simulation, the participants acted as leaders of hypothetical corporations who made successive decisions across 10 rounds about how many consumer goods to produce. The primary goal for the participants in the simulation was to maximize their profit relative to another player's hypothetical corporation by producing more goods in a competitive marketplace, thus using competitive payoff rules (although others are possible) [63]. Producing goods necessitated the use of fossil fuel inputs, with their associated greenhouse gas emissions, which in turn affected an account representing the health of the climate. In each round, the participants chose to increase, to make no change, or to decrease production. If the net production of the paired competitors was greater than 0 , the climate account dropped. In order to prevail against the competitor, they had to keep the climate health account from falling below a threshold. As long as the joint production of the competitors was a net of 0 , the climate account was unaffected. If the combined production was less than 0 , the climate account increased. The algorithm to calculate the degree to which the pairs' collective decisions affected the climate each round was nonlinear, consistent with the fact that global emissions have a non-uniform effect on the climate.

In addition, the profit each round was tied to the value of the climate account. The participants could make more profit in the context of a healthy climate than in a degraded one. Thus, the result of each round was a joint outcome of the participants' choices in that round (e.g., a prisoner's dilemma-type game, performed successively), as well as the state of the climate. In each round, the participants faced a decision in which they had to monitor and project the likely effect of their various production choices on multiple variables: their company's current worth, their competitor's worth, and the climate health account. The set of interconnections among these variables across 10 rounds allowed for a huge variety of possible strategies, which should have enhanced behavioral identification. Finally, if they won the simulation by having a higher worth than their competitor while still keeping the climate account above a threshold, they were offered extra course credit, which was intended to enhance emotional identification. Personal investment was also expected to be positively influenced by the fact that they were playing with a real person from their course, although they were anonymous to each other.

\subsection{Predictions}

As mentioned previously, we predicted that participating in a social dilemma simulation would have positive, rather than negative, impacts on climate-protective engagement [35]. However, engagement with climate change is multi-faceted, and can take many forms. Below, we explicate hypotheses for the specific forms of climate change engagement we employed in our study.

Most people are not highly informed about the science of climate change [64]. However, our study did not aim to give participants factual information about the science of how climate change occurs, but instead to help them understand how a social dilemma affects decisions regarding behaviors that can lead to climate change. Thus, we expected that engagement in the simulation would result in higher confidence among the participants that they understood climate change in the context of social dilemmas. Because we expected the social dilemma simulation would help the participants see the potential negative impacts climate change will have, as well as how their own behaviors can con- 
tribute to it (as discussed previously with regard to Protection Motivation Theory), we also hypothesized that the participants who experienced the simulation would express stronger global warming beliefs, such as the belief that climate change is real, is human-caused, and will have negative impacts.

We also expected that the participants, upon experiencing the dilemma tradeoffs themselves, would experience the difficulties they and others have in making decisions that favor the long-term common good over short-term personal benefits. Not trusting that enough people in the world would overcome the social dilemma pressures, we hypothesized that they would then become more concerned about the environment. This concern could translate into more motivation to do their part. Some research suggests that concern can lead to no change [65] or other outcomes, such as defensive reactions [66,67]; however, perceiving a severe threat when an effective action is clear and manageable can lead to action [51-53,68]. Thus, following Capstick, we expected that the participants would be more willing to take responsibility for their own behavior, and would indicate higher motivation to change their own behavior [35]. Finally, greater confidence in understanding social dilemmas, concern and motivation should lead to more willingness to act to mitigate climate change and to take the opportunities for doing so when we presented them. Although knowledge of climate change itself has not been readily associated with mitigation action [69], people who consider themselves better informed about the issue of climate change, regardless of whether they are correct, consider the risks associated with the issue to be higher [48]. In turn, people are more likely to have intentions to engage in climate-change-mitigating behavior when they also believe that global warming poses a great risk [70,71]. In addition, previous research on resource dilemmas has found that people who reported more internal motivation engaged in more and longer-lasting environmentally-supportive actions [72,73]. Therefore, we hypothesized that participation in a social dilemma simulation would increase the likelihood of acting in a climate-protective manner.

\section{Materials and Methods}

\subsection{Design}

In order to determine whether participating in the simulation fostered climate-protective knowledge, motivation, concern and actions, we compared three groups of college students: (1) students who took part in the simulation who were in an environmental studies course at the time, (2) a control condition of those who did not take part in the simulation but were in an environmental studies course, and (3) a control condition of those who were neither in an environmental studies course nor took part in the simulation. Previous research has found that an environmental course can increase self-determined motivations [74], and would also be expected to increase knowledge of climate change. Therefore, having that control condition was helpful for disentangling the role of the simulation from the role of learning about the environment. Then, as a way to ensure that simply being in any class, or alternately, that any kind of cohort effects (e.g., all groups learning about climate change from the media), were not responsible for any effects we observed, we added the other control group that neither took part in the simulation nor learned about the environment in class. Because the simulation was not considered relevant enough for a non-environmental course to justify the use of class time to run it, it was not possible to collect data for a group which was not in an environmental class but who also took part in the simulation.

In addition to the between-group comparisons, a large subset of the participants completed a pre-test and a post-test of most of the variables in order to allow withinparticipant comparisons. In this way, the participants served as their own control, which helped to eliminate the possibility that the effects are due to any differences in the kinds of people who were in each group. Mitigating against this concern, however, it should be noted that the environmental studies courses were intro-level general education courses and not designed for science or sustainability majors. One course was Psychology and Sustainability, and the other was Introduction to Sustainability for non-science majors. 
The first author conducted the same learning module in both classes, in which the science and human drivers of climate change were covered, as well as the dynamics of social dilemmas, and possible human solutions. Overall, the focus of both courses was the causes of, consequences of and solutions to environmental problems. Specifically, the Psychology and Sustainability course consisted of instruction regarding basic principles of psychology aimed toward understanding how humans affect nature. The Introduction to Sustainability course content was more broad, and included modules on how several disciplines, including psychology, and others such as geography and economics, could address environmental problems. In that course, instructors from the various disciplines presented modules for the students. Thus, a module targeted at social dilemmas as one human-related cause of climate change, along with the discussion of the inherent traps and ways to overcome them, fit well in both courses. In addition, the dependent variables listed below, including knowledge, concern, global warming beliefs, motivation and action, were consistent with the goals for learning in the courses. The pre-test was performed at the start of the semester and the post-test near the end of the semester, allowing for approximately 12 weeks between the pre- and post-administrations. The post-test followed within 1-2 weeks after the simulation. It is also important to note that because of the limitations on the length of time it took to run the simulation during the class, there were restrictions on how much class time could be devoted to the study. Therefore, not all of the participants received all of the measures. Altogether, we employed a 2 (Time: pre-test; post-test) X 3 (Condition: Environmental Studies plus Simulation; Environmental Studies, No Simulation; No Environmental Studies, No Simulation) mixed-factors design with the repeated measures on the Time variable. Figure 1 provides an overview of the design and data collection.

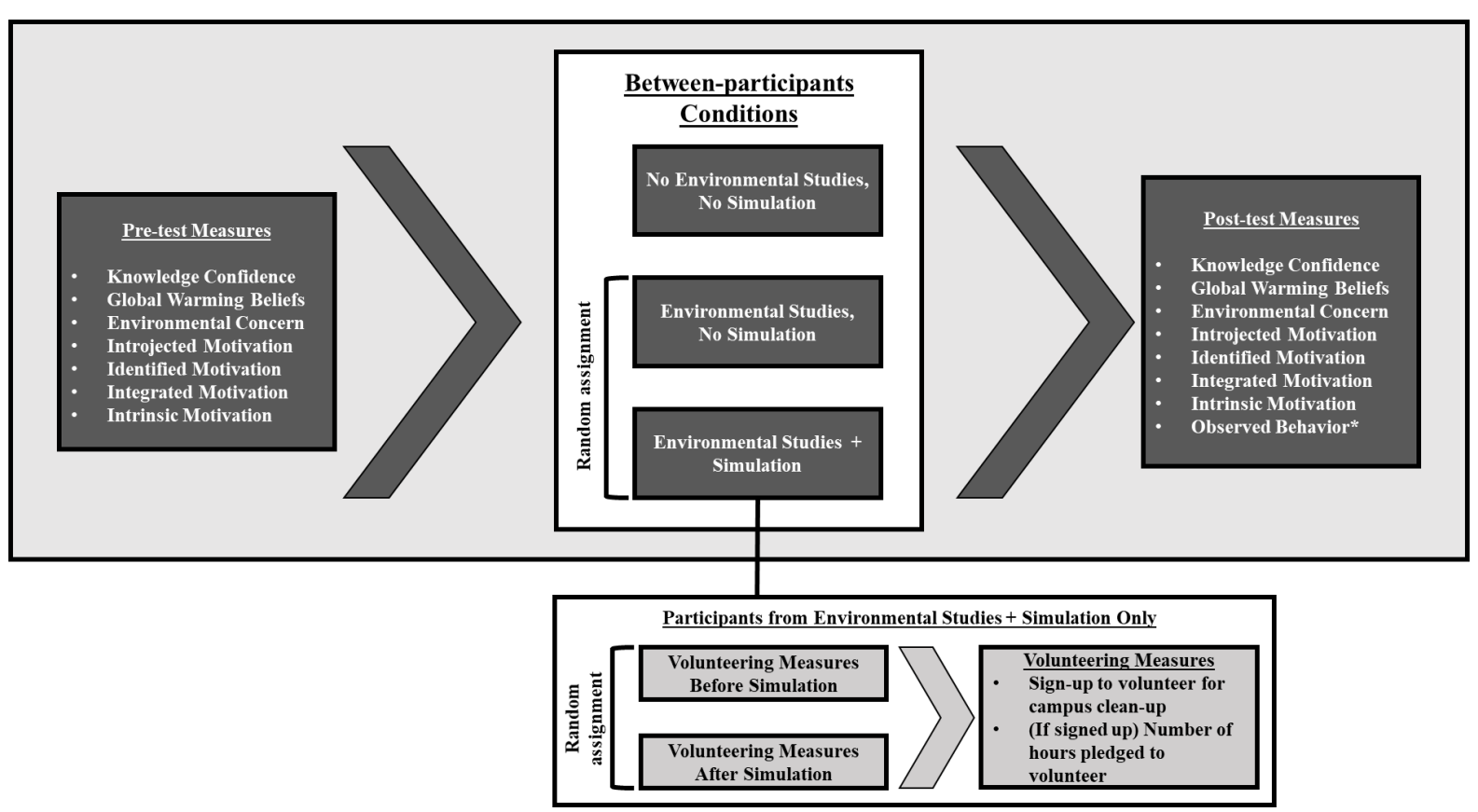

Figure 1. Overview of study design, measures and conditions. A significant interaction of Time (pre-test; post-test) $\mathrm{x}$ Condition (Env St plus Sim; Env St, No Sim; No Env St, No Sim) would indicate whether the changes pre- to post-test were higher for the participants who took part in the simulation, as predicted. Due to survey's length restrictions, the students were randomly assigned to receive parts of the survey, meaning not all of the DVs were asked for all of the participants (see Table 1 for the $\mathrm{N}$ for each measure by the condition) * Indicates that this measure was only available for Env St plus Sim and the No Env St, No Sim conditions due to survey limitations and course availability restrictions. The observed behavior measures were asked post-test only because they were highly susceptible to the testing effects (e.g., asking a participant to sign the same petition twice), and were therefore unsuitable for repeated measures. 
In addition to the larger mixed-participants design, a subset of the students who participated in the simulation were asked by a confederate (whom they believed was not involved with the study) to volunteer for a pro-environmental program. Using random assignment, half of the participants were approached before they participated in the simulation and half were approached after the simulation.

Finally, the students who perform a research activity as a part of a course may feel that they need to appear to be learning, or to otherwise please the instructors. Consequently, the presentation bias to answer in a socially desirable manner may be particularly strong in such a setting. We accounted for this possibility by replicating all of our analyses while statistically controlling for the participants' bias toward responding in a socially desirable manner.

\subsection{Participants}

A total of 397 participants participated in the study. After $13 \%(N=53)$ of the sample were removed because they either failed an attention check $(\mathrm{N}=6)$, or because they indicated that they did not answer questions accurately $(\mathrm{N}=47), 344$ participants remained. Of this total, 226 were female, 112 were male, 1 was non-binary, and 5 did not report their gender. The average age of the sample was 20.73, $\mathrm{SD}=4.04, \mathrm{MD}=20$. The racial identity was heavily white/Caucasian ( $\mathrm{N}=280)$, with another 13 who were Black/African American, 9 Latinx/Hispanic, 1 Asian, 14 who indicated other races or ethnicities, and 27 who chose not to report. For the conditions, two groups were composed of students in a course focused on the environment in which the topic of climate change was covered, of which 137 took part in the simulation and 85 did not. Another 112 participants were in a control group of students who were taking a different course and who did not take part in the simulation. All of the analyses reported herein were for students who gave their informed consent to use their data in this study. The research conformed to the guidelines of the American Psychological Association ethical code, and is in accordance with the Declaration of Helsinki. The protocol was approved by the IRB of York College of Pennsylvania, with the ID of F13BS001.

\subsection{Materials and Measures}

\subsubsection{Simulation Materials}

In order to administer the simulation, an excel spreadsheet was used to keep track of the decisions of the participants. It showed the results of each set of calculations for each round for the participant's hypothetical company's worth, their competitor's worth, and the climate account.

\subsubsection{Primary Dependent Variables}

Knowledge Confidence. The participants self-reported their confidence in their knowledge and understanding of nine topics: climate change, social dilemmas, social traps, temporal traps, decision-making strategies in social dilemmas, the effects on the climate of overconsumption, the effects on the environment of overpopulation, reasons for environmental problems, and sustainability strategies. The confidence in each item was rated on a 7-point scale that ranged from 1 (little to no confidence) to 4 (the same as the average person) to 7 (extremely confident). Because the reliability of the items using Cronbach's alpha was high, at 0.919 , the items were averaged for each participant in order to create a composite score for their confidence in their knowledge.

Global Warming Beliefs. The skepticism regarding whether climate change is real was assessed with the seven items used by Feinberg and Willer [66]. The questions addressed the respondent's certainty that global warming is real, e.g., "How solid is the evidence that the earth is warming", rated on 6-point scales from 1 (not at all) to 7 (extremely). The Cronbach's alpha was high, at 0.92, and each participant's global warming belief score was a total for the seven items. 
Environmental Concern. Concern for the environment was measured with the participants' agreement with five statements taken from Ellis and Thompson [75], as used by Dutcher et al. [76]. These statements were: (1) "If things continue on their present course, we will soon experience a major ecological catastrophe", (2) "The problems of the environment are not as bad as most people think" (reverse scored), (3) "We are fast using up the world's natural resources", (4) "People worry too much about human progress harming the environment" (reverse scored), and (5) "We are spending too little money on improving and protecting the environment". The ratings were on 5-point Likert scales, from 1 (Strongly Disagree) to 5 (Strongly Agree). The reliability was satisfactory, at alpha $=0.785$; therefore, the items were summed per participant to create an environmental concern score.

Motivation Toward the Environment. The six subscales of the Motivation Toward the Environment Scale (MTES) [77] were based upon Self-Determination Theory [78,79], which suggests that motivation types differ in terms of quality and source along a spectrum of self-determination. For the purposes of our analysis, we focused on the four types of motivation most closely related to internalized motivation: "introjected" (to avoid negative emotions such as guilt), "identified" (goals are important to achieve something), "integrated" (action because of values integrated in self-identity), and-the most selfdetermined-"intrinsic" (behaviors lead to high satisfaction and do not feel like a sacrifice). Each type of motivation was assessed with the four items presented by Pelletier et al. [77] and rated on how close each item corresponded to the participant's motives for engaging in environmental behaviors, from 1 (Does not correspond at all) to 7 (Corresponds exactly). The four items for each subscale were averaged for each participant.

Observed Behavior. We asked a subset of the participants to do each of the following: (1) sign the Graduation Pledge of Social and Environmental Responsibility (http:/ / www. graduationpledge.org/ accessed 1 July 2021), (2) donate a $\$ 50$ gift card if they won it in our drawing, (3) put their name on the volunteer list for a month-long environmental effort, (4) sign a petition to Congress urging them to pass the No Child Left Inside Act, (5) sign a petition for increased government legislation to address climate change, and (6) sign a petition to US food manufacturers to stop clearing rainforests. The total number of items the participant chose to do was used as the dependent variable (referred to in the tables as 'Observed Behavior'), Cronbach's alpha $=0.764$. We asked for these behaviors only in the post-test because of likely testing effects (e.g. asking the participants to sign the same pledge or petition again), and so they were not included as repeated measures.

The behaviors we assessed were chosen because they are actual behaviors that we could observe within the survey itself, rather than self-reported behaviors we could not observe, which boosts the ecological validity of our findings. Collectively, the actions we offered constitute individual behaviors known as citizenship, activist, or public-sphere behaviors $[8,80,81]$. Although other behaviors, such as lifestyle behaviors-also known as private-sphere behaviors, such as consumer choices-are crucial, we wanted to test our simulation first with the more easily observable behaviors, with the hope for positive spillover to lifestyle-type behaviors [82] to be examined in a future study. In addition, we analyzed the behaviors as an index, rather than separately, under the principle that aggregating behaviors can yield a more reliable measure and tends to be higher in criterion validity [83] and predictive validity [84].

Volunteering for Campus Action. We asked the participants from a subset of the Environmental Studies with Simulation group, either before or after they took part in the simulation, to indicate if they would volunteer hours for on-campus environmental projects of their choosing, such as a campus cleanup that would require them to spend time walking around the campus picking up trash. For this dependent variable, we assessed the percentage who volunteered in each condition, and the number of hours they offered to volunteer. 


\subsubsection{Additional Variables}

Evaluation of the Simulation. Among the students who took part in the simulation, we used six single-item measures to obtain feedback from the students about their experience of the simulation. The participants were asked how engaged they were during the simulation, how excited they were to meet the challenge, how confused they were by how the simulation worked, and how unsure they were about how to make the best decisions. These questions were rated from 1 (not at all) to 7 (a great deal). The participants were also asked to rate the degree to which the simulation captured elements of the real-life processes associated with social dilemmas, from 1 (not very well at all) to 7 (extremely well). Finally, they were asked for the extent to which they believed they learned more effectively about social dilemmas from the simulation compared to a regular class lecture, from 1 (strongly feel they would have learned better from a lecture) to 7 (strongly feel they learned better with the simulation).

Covariate. Because the simulation took place in the context of a course, the students may have been motivated to appear to have learned or have been positively affected, and to merely report answers that made them look socially desirable. Thus, we included a commonly used measure of an individual's tendency toward Socially Desirable responding [85] to use as a covariate. The 17 items included statements that are unlikely to be true for most people, such as "I have never intensely disliked someone" and "No matter who I'm talking to, I am always a good listener". Social desirability bias is higher the more often the respondent is unwilling to acknowledge flaws, such as by denying that they have disliked someone intensely. The scores were calculated as the total number of questions for which the respondent answered in a highly socially desirable manner.

\subsection{Procedure}

The participants were given instructions for how the simulation would work. It was explained that they were acting as corporate heads making decisions every 10 weeks about how much to change the production of goods to sell, from 7 options: decrease $15 \%, 10 \%$, or $5 \%$; no change; or increase $5 \%, 10 \%$, or $15 \%$. They were told that their goal was to win against a competing company, which was another student, by having the highest corporate worth at the end. If they won, they would receive an extra class credit of $5 \%$ added to an exam. Each company began the simulation with a hypothetical value of $\$ 250,000$.

The participants were also told that producing the goods required the use of fossil fuel energy and thus contributed to global warming. During the simulation, the effect of their production on the climate was illustrated with a financial indicator of a hypothetical climate health account, which began with a value of $\$ 500,000$. The rules of the simulation were such that both competitors would lose if the climate account fell below $\$ 10,000$.

The computations were made using two matrixes that were shown to the participants: one for the change to the participant's profits, and the other for the effect on the climate (provided in Appendix A). In each matrix, the cells indicated the effect of the joint decisions. The participants were shown the matrices and a couple of examples of the computations. For instance, in the company worth change matrix, if the participant chose the maximum production of $15 \%$ and the paired player chose $0 \%$, then the first player would have their wealth increased by $6 \%$, and the other player would lose $3 \%$. The participants were also shown what would happen to the climate under various decisions for the companies. For instance, if both the participants chose to increase production by $5 \%$, the climate account would be decreased by $20 \%$. If one chose to increase $5 \%$, but the other decreased $5 \%$, the net effect would be 0 and the climate account would be unchanged. If they both decreased by $5 \%$ then the climate account would increase by $20 \%$. The numbers in the matrixes were chosen such that the relative gains and losses could be psychologically felt each round, the climate account could be depleted within a few rounds if the players made the maximum production choices, and the climate account could increase by an easily perceptible amount each round. 
The participants were told that the profit calculations each round were lessened or augmented based upon the status of the climate account. Thus, in addition to their own worth and their competitor's worth, they needed to keep a close eye on the climate account each round. More profit could be made when the climate account was high. In this way, we included an incentive to try to keep the climate account high beyond just staying above the minimum threshold.

After the instructions and demonstrations were provided, the participants were split into two groups and put into separate rooms. They were then randomly assigned to pair with someone in the other room. Then, the simulation began and they were told to make the first production decision, and to write their choice on a slip of paper to give to the facilitator. The slips were gathered from the participants in one room and taken to the other room to distribute to the paired participant, keeping them anonymous to each other. The participant entered their own decision and their partner's decision into the excel spreadsheet to see the effects on their own company, the competing company, and the climate account. Based upon the outcomes, the participant would make another decision, and this process was repeated for 10 rounds or until the resource fell below a certain threshold, at which point the paired participants both lost the simulation.

After 10 rounds, the participants were given a link to a survey which contained the demographic questions, dependent variables and covariates. The participants in the classes who did not take part in the simulation completed the same survey at the same time in the semester. In addition, a subset of the participants in all of the groups completed the same survey at the beginning of the semester so that within-participant comparisons could be made. Finally, a different subset of the participants was randomly assigned to take the survey before or after they took part in the simulation.

\section{Results}

\subsection{Evaluation of the Simulation}

The students reported being highly engaged with $(M=5.86, S D=1.34)$ and excited to meet the challenge of $(\mathrm{M}=5.01, \mathrm{SD}=1.46)$ participating in this simulation, suggesting appropriate emotional identification [62]. The observation of the participants in real time while they were participating in the simulation gave us some anecdotal evidence that they were engaged: their physical demeanor (e.g. shaking heads, facial expressions of surprise or smiles) and verbal comments (e.g. utterances of frustration such as "ughs" and some swearing) suggested that they were personally invested in the outcomes.

The participants were not confused about how the simulation worked $(\mathrm{M}=3.03$, $\mathrm{SD}=1.91)$. However, they were somewhat unsure of how to make the best decisions $(\mathrm{M}=4.03, \mathrm{SD}=1.70)$, which is optimal, given that we did not want the participants to believe there was an easy set of best decisions. They also believed that the simulation captured the real-life processes associated with social dilemmas $(M=5.64, S D=1.22)$, supporting cognitive identification, and that they learned better about social dilemmas with the simulation than they would with a lecture $(\mathrm{M}=5.59, \mathrm{SD}=1.50)$.

The simulation elicited an appropriate range of strategies supporting behavioral identification. For each of the 10 rounds, there were participants who chose each of the 7 options. The mean decisions each round were positive, indicating net increases in production, suggesting that the participants were generally choosing profit over climate, especially at the end, with the highest production $(M=8.00)$ chosen in the last round. There was one exception, which was the first round in which the average production was -0.725 , indicating an initial willingness to reduce production. The standard deviations for the production decisions each round were large, ranging from a low of 7.46 in round 2 to a high of 9.34 in round 5, indicating that there was wide variation, and that no one series of decisions was highly favored.

The value of the climate account, which began at $\$ 500,000$, varied greatly after the final round as well. The account ranged from under the threshold of $\$ 10,000$ to over $\$ 3.5$ million, with an average of around $\$ 400,000$ and a standard deviation of just over $\$ 750,000$. The 
participant company's worth similarly varied after starting at $\$ 250,000$ : it ranged from a low of $\$ 140,000$ to almost $\$ 1.6$ million, with a mean of just over $\$ 500,000$ and a standard deviation of almost $\$ 350,000$. Again, the focus of this research was not specifically on the strategies chosen or the outcomes within the simulation. The above data are provided as a means of showing that the responses to the simulation were varied, as was intended.

\subsection{Analytical and Reporting Strategy for the Hypothesis Testing \\ 3.2.1. Between-Participant Analyses}

First, we compared the knowledge, beliefs, concern, motivation and actions between the students who had participated in the simulation and the students who had not. Oneway ANOVAs were computed separately for each composite dependent variable in order to compare the three groups: people who participated in the simulation within an environmental studies course, people in an environmental studies who did not participate in the simulation, and people who were in another (not environmentally-focused) course who did not participate in the simulation. We then replicated each of these analyses with separate one-way ANCOVAs in order to see if our results held when controlling for social desirability bias.

\subsubsection{Within-Participant Analyses}

Second, we examined whether the students in all three groups reported greater climateprotective knowledge confidence, beliefs, concern and motivation late in the semester (i.e., after the target group completed the simulation, from here on referred to as 'post-test') compared to early in the semester (i.e., before the simulation, from here on referred to as 'pre-test'). If our hypotheses were correct, and participation in the simulation promotes climate-protective knowledge confidence, beliefs, concern and motivation, then we would expect an interaction between the condition and time (pre-test; post-test) such that those in an environmental studies class may change, but those who also took part in the simulation would change more. In order to test this possibility, we ran a 2 (Time: pre-test; post-test) X 3 (Condition: Environmental Studies plus Simulation; Environmental Studies, No Simulation; Neither Environmental Studies, Nor Simulation) mixed-measures ANOVA, with repeated measures on the Time variable. The repeated-measures analyses allowed us to compare the participants to their own respective baselines, further helping us rule out the possibility that significant effects may be due to pre-existing differences in the types of people who signed up for the different classes. Again, we replicated these analyses while controlling for social desirability bias. Because only a subset of the sample was available for the repeated measures, the Ns were lower in these analyses than in the between-participants analyses.

\subsubsection{Volunteer for Action Measures}

In an additional randomly assigned subset, the participants who were asked to volunteer to perform climate-protective behaviors before taking part in the simulation were compared to a different group who were asked after taking part in the simulation in two sets of analyses: first, we compared the percentages of those who volunteered with a z-test; second, we ran a one-way ANOVA with those in each group who did volunteer, in order to compare the number of hours they committed to volunteering.

\subsection{Hypothesis Testing}

For all of the measures of climate-protective knowledge, concern, motivation and actions, the results for the between-participant analyses with and without controlling for social desirability are reported in Table 1 . The results for the interaction analyses are reported in Table 2. Figure $2 \mathrm{a}, \mathrm{b}$ and Figure $3 \mathrm{a}-\mathrm{c}$ give visualizations of the significant interactions and follow-up analyses for knowledge confidence, environmental concern, and motivation. 


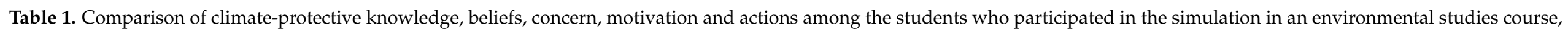

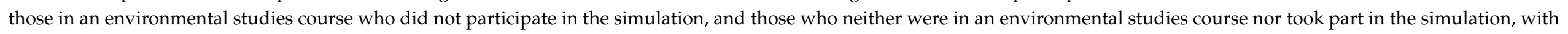
follow-up significance testing.

\begin{tabular}{|c|c|c|c|c|c|c|c|c|c|c|}
\hline \multirow[b]{2}{*}{ Dependent Variable } & \multirow[b]{2}{*}{ df (between, within) } & \multirow[b]{2}{*}{ F-Statistic } & \multirow[b]{2}{*}{$p$-Value } & \multirow[b]{2}{*}{$\eta^{2} p$} & \multicolumn{2}{|c|}{ Env $S t+\operatorname{Sim}$} & \multicolumn{2}{|c|}{ Env St, No Sim } & \multicolumn{2}{|c|}{ No Env St, No Sim } \\
\hline & & & & & $\mathbf{N}$ & Mean (SD) & $\mathbf{N}$ & Mean (SD) & $\mathbf{N}$ & Mean (SD) \\
\hline Knowledge Confidence & $(2,238)$ & 23.51 & $<0.001$ & 0.165 & 81 & $4.84^{\mathrm{a}}(1.05)$ & 73 & $4.14^{\mathrm{b}}(1.06)$ & 87 & $3.71^{\mathrm{c}}(1.11)$ \\
\hline Global Warming Beliefs & $(2,137)$ & 4.96 & 0.008 & 0.068 & 26 & $29.50^{\mathrm{a}}(5.57)$ & 66 & $26.02^{b}(4.60)$ & 48 & $26.19^{b}(5.19)$ \\
\hline Environmental Concern & $(2,256)$ & 12.30 & $<0.001$ & 0.088 & 99 & $20.34^{\mathrm{a}}(3.26)$ & 73 & $18.86^{\mathrm{b}}(3.56)$ & 87 & $17.94^{\mathrm{b}}(3.23)$ \\
\hline Introjected Motivation & $(2,137)$ & 1.36 & 0.260 & 0.019 & 26 & $4.24(1.52)$ & 66 & $3.71(1.43)$ & 48 & $3.74(1.41)$ \\
\hline Identified Motivation & $(2,137)$ & 4.56 & 0.012 & 0.062 & 26 & $5.39^{\mathrm{a}}(1.21)$ & 66 & $4.45^{\mathrm{b}}(1.41)$ & 48 & $4.78^{\mathrm{ab}}(1.32)$ \\
\hline Integrated Motivation & $(2,137)$ & 5.27 & 0.006 & 0.071 & 26 & $4.37^{\mathrm{a}}(1.37)$ & 66 & $3.40^{\mathrm{b}}(1.27)$ & 48 & $3.78^{a b}(1.29)$ \\
\hline Observed Behavior & $(1,110)$ & 6.21 & 0.014 & 0.053 & 73 & $3.25(1.82)$ & & & 39 & $2.38(1.58)$ \\
\hline \multicolumn{11}{|c|}{ Dependent Variable, Controlling for Social Desirability } \\
\hline Knowledge Confidence & $(2,237)$ & 23.27 & $<0.001$ & 0.164 & 81 & $4.84^{\mathrm{a}}(1.05)$ & 73 & $4.14^{\mathrm{b}}(1.06)$ & 87 & $3.71^{\mathrm{c}}(1.11)$ \\
\hline Global Warming Beliefs & $(2,136)$ & 5.56 & 0.005 & 0.076 & 26 & $29.50^{\mathrm{a}}(5.57)$ & 66 & $26.02^{b}(4.60)$ & 48 & $26.19^{\mathrm{b}}(5.19)$ \\
\hline Environmental Concern & $(2,237)$ & 9.67 & $<0.001$ & 0.075 & 99 & $20.34^{\mathrm{a}}(3.26)$ & 73 & $18.86^{\mathrm{b}}(3.56)$ & 87 & $17.94^{\mathrm{b}}(3.23)$ \\
\hline Introjected Motivation & $(2,136)$ & 1.75 & 0.177 & 0.025 & 26 & $4.24(1.52)$ & 66 & $3.71(1.43)$ & 48 & $3.74(1.41)$ \\
\hline Identified Motivation & $(2,136)$ & 5.41 & 0.006 & 0.074 & 26 & $5.39^{\mathrm{a}}(1.21)$ & 66 & $4.45^{\mathrm{b}}(1.41)$ & 48 & $4.78^{\mathrm{ab}}(1.32)$ \\
\hline Integrated Motivation & $(2,136)$ & 5.84 & 0.004 & 0.079 & 26 & $4.37^{\mathrm{a}}(1.37)$ & 66 & $3.40^{\mathrm{b}}(1.27)$ & 48 & $3.78^{a b}(1.29)$ \\
\hline Observed Behavior & $(1,91)$ & 3.98 & 0.049 & 0.042 & 55 & $3.07(1.79)$ & & & 39 & $2.38(1.58)$ \\
\hline
\end{tabular}

Notes: Letters indicate significant differences $(p<0.05)$ with Bonferroni corrections; bold indicates a change in the statistical significance when controlling for social desirability. 


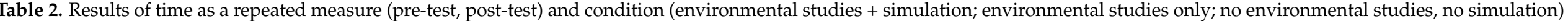
for mixed-measure ANOVAs and ANCOVAs (controlling for social desirability bias) on climate-protective knowledge, beliefs, concern and motivation.

\begin{tabular}{|c|c|c|c|c|}
\hline \multicolumn{5}{|c|}{ Interaction (Time X Condition) } \\
\hline Dependent Variables & df (between, within) & F-Statistic & $p$-Value & $\eta^{2} p$ \\
\hline Knowledge Confidence & $(2,147)$ & 11.76 & $<.001$ & 0.138 \\
\hline Global Warming Beliefs & $(2,82)$ & 0.22 & 0.805 & 0.005 \\
\hline Introjected Motivation & $(2,82)$ & 0.70 & 0.498 & 0.017 \\
\hline Identified Motivation & $(2,82)$ & 5.18 & 0.008 & 0.112 \\
\hline Integrated Motivation & $(2,82)$ & 3.84 & 0.026 & 0.086 \\
\hline Intrinsic Motivation & $(2,82)$ & 4.08 & 0.020 & 0.091 \\
\hline \multicolumn{5}{|c|}{ Dependent Variable, Controlling for Social Desirability } \\
\hline Knowledge Confidence & $(2,146)$ & 11.71 & $<0.001$ & 0.138 \\
\hline Global Warming Beliefs & $(2,81)$ & 0.251 & 0.779 & 0.006 \\
\hline Environmental Concern & $(2,146)$ & 2.62 & 0.076 & 0.035 \\
\hline Introjected Motivation & $(2,81)$ & 0.40 & 0.674 & 0.010 \\
\hline Identified Motivation & $(2,81)$ & 4.83 & 0.010 & 0.107 \\
\hline Integrated Motivation & $(2,81)$ & 3.50 & 0.035 & 0.080 \\
\hline Intrinsic Motivation & $(2,81)$ & 3.79 & 0.027 & 0.086 \\
\hline
\end{tabular}

Note: Bold indicates a change in statistical significance when controlling for social desirability. 


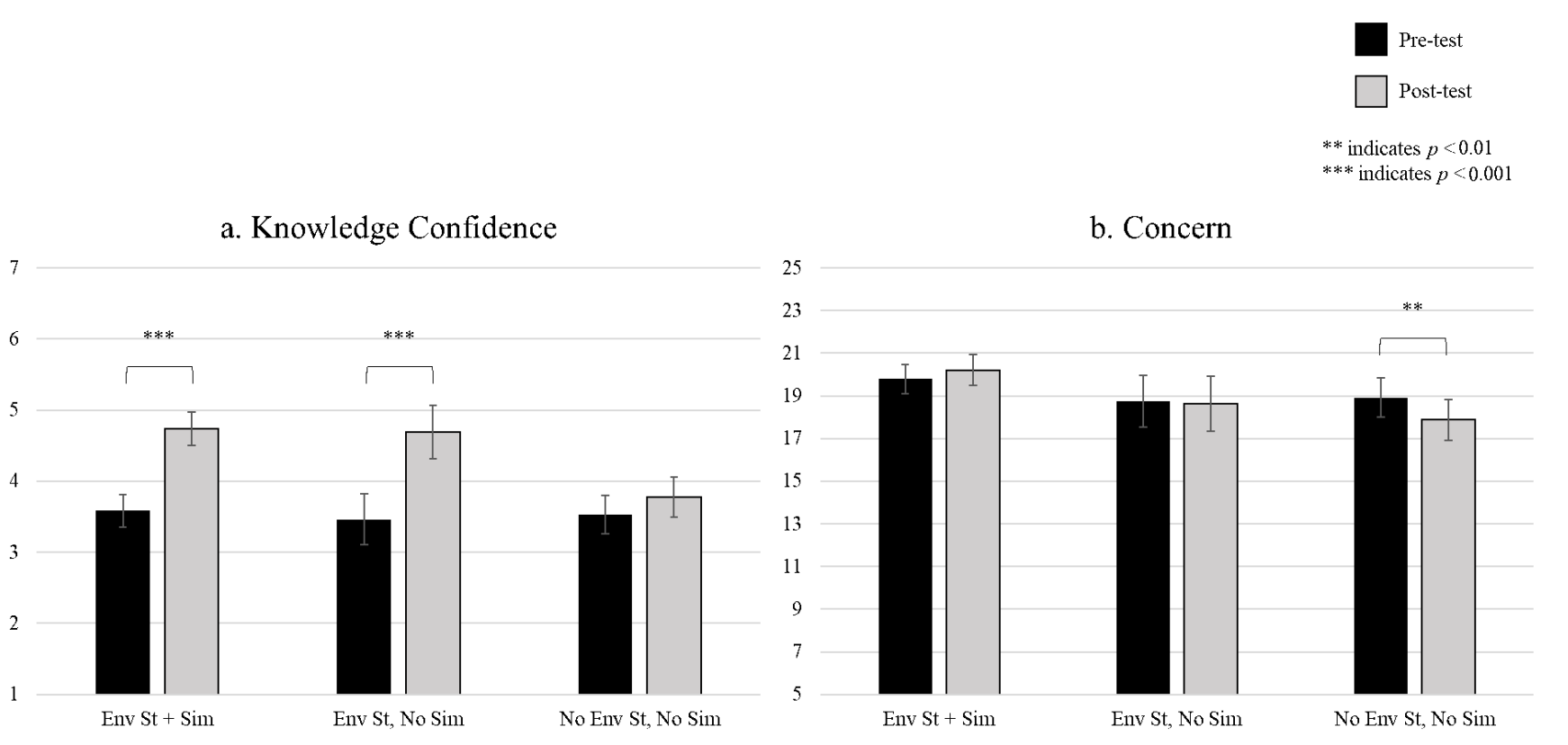

Figure 2. (a,b). Significant interaction of time (pre- vs. post-test) and condition (environmental studies + simulation; environmental studies only; no environmental studies, no simulation) on knowledge confidence and environmental concern, with follow-up analyses.

a. Identified Motivation

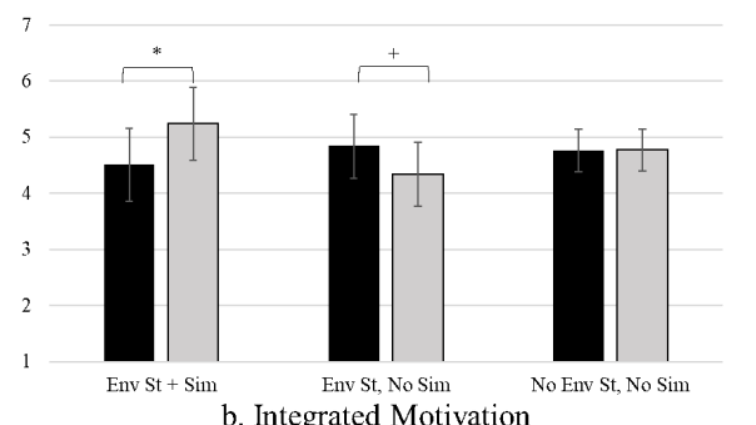

Pre-test

Post-test

indicates $p<0.05$ + indicates $p<0.10$

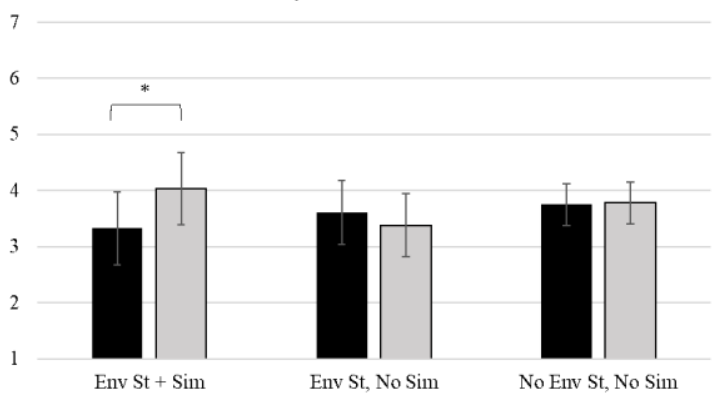

c. Intrinsic Motivation

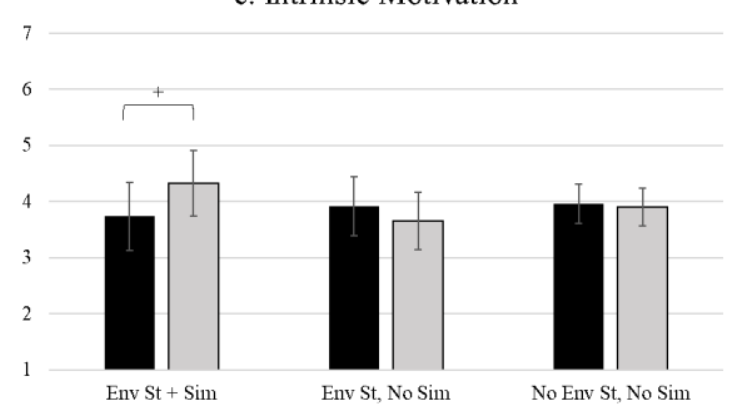

Figure 3. (a-c). Significant interactions of time (pre- vs. post-test) and condition (environmental studies + simulation; environmental studies only; no environmental studies, no simulation) on climate-protective motivation with followup analyses.

\subsubsection{Knowledge Confidence}

As expected, the students who participated in the social dilemma simulation reported higher confidence that they understood the social dilemma context of climate change, both in the pre-test/post-test comparisons (within-participant analyses, see Table 2 and Figure 2a) and in contrast to the students who did not participate in the simulation 
(between-participant analyses, see Table 1). The students taking a sustainability class who did not take part in the simulation scored between the simulation participants and the controls. The results remained consistent when replicated whilst controlling for social desirability bias.

\subsubsection{Global Warming Beliefs}

The between-participant analyses suggested that the group that received the simulation reported significantly stronger beliefs in global warming than the two groups which did not participate in the simulation (Table 1). However, the within-participants comparisons were not significant (Table 2), suggesting that the difference between the groups may be spurious, or that if there is an effect it may be weak, necessitating replication in order to draw any conclusions. A similar pattern of results was obtained when controlling for social desirability bias.

\subsubsection{Environmental Concern}

As predicted, the simulation participants expressed greater environmental concern compared to the two other groups who did not participate in the simulation, and this effect remained significant when controlling for social desirability (Table 1). Unexpectedly, whereas we did find a significant interaction between the time and condition in our withinparticipant analyses, the follow-up analyses suggest that the simulation likely did not increase environmental concern among the simulation participants (Table 2 and Figure 2b). Instead, we found that our group of students in the control (non-environmental) course decreased in their environmental concern over time. When controlling for social desirability, the interaction was no longer statistically significant.

\subsubsection{Motivation}

Our hypothesized effects of participation in the simulation were supported in the analyses of three out of four types of self-directed motivation: identified, integrated and intrinsic. The between-participants analyses suggest that the students in the environmental studies course who participated in the simulation reported stronger identified, integrated and intrinsic motivation than the environmental studies group with no simulation (Table 1). The effect for intrinsic motivation was initially marginally significant $(p=0.052)$ and became statistically significant when controlling for social desirability bias $(p=0.029$; Table 1$)$. Moreover, and in-line with our hypotheses, the students who participated in the simulation reported stronger identified, integrated and intrinsic motivation after completing the simulation compared to the pre-test measures (Table 2, Figure 3a-c), and these results held when controlling for social desirability bias. No significant increases in motivation were observed in the other two groups. The between-participant analyses did not show any significant differences among the three groups regarding introjected motivation, with or without controlling for social desirability bias. Additionally, we found no significant interaction on introjected motivation via the within-participant analyses.

\subsubsection{Observed Behavior}

As predicted, the students who participated in the simulation were more likely to perform a series of six pro-environmental behaviors, as measured by the aggregate variable, compared with the students who did not complete the simulation (Table 1). Due to technical constraints, none of those in the environment studies, no simulation group received the behavior measures survey. Thus, from this analysis alone we are not able to compare the effect of an environmental studies course alone with that of participating in the simulation. The analysis below, however, add to the argument that the simulation was uniquely effective in producing climate-protective behavior. 


\subsubsection{Volunteering for Campus Action}

As predicted, the students who were randomly assigned to be asked after participating in the simulation were significantly more likely to volunteer $(n=29,50 \%)$ to help pick up litter around the campus or other eco-friendly actions, as compared with the other students who were asked to volunteer before they took part in the simulation $(n=13,21 \%)$, $z=3.32, p<0.001$. Of those the participants who did volunteer to assist, the students who were asked after the simulation said they would be willing to volunteer for more hours $(M=4.56, S D=2.89)$ than those who were asked before they took part in the simulation $(M=2.38, S D=2.89), \mathrm{F}(1,40)=5.62, p=0.03$.

\section{Discussion}

In this paper, we evaluated a novel social dilemma simulation that was specifically designed to help people experience and understand the decision-making processes which contribute to the human dimensions of climate change. In addition to evaluating the simulation as an educational tool, we offer a novel extension of the previous research on social dilemma simulations by shifting the focus of these simulations from how people act during the simulation to how they think, feel, and act after the simulation has been completed. Specifically, we predicted and found, comparing the simulation participants to the non-participants, as well as the participants to themselves before and after the simulation, that the people who participated in our simulation were more confident in their knowledge of climate change and its relationship to social dilemmas, reported more self-determined motivation to help, and performed more climate-mitigating behaviors. When changes within the other groups who did not complete the simulation were present, our analyses suggested that our simulation participants may have experienced stronger climate-friendly changes on each measure than the other groups. Moreover, the effects remained largely consistent when controlling for social desirability bias, suggesting that our results are unlikely to be attributable to self-presentation concerns related to pleasing the teacher in a classroom setting.

Our results suggest that our new climate-change social dilemma simulation may be a potentially useful educational tool. It was rated as highly engaging by the participants, and is unique in that it links climate change to decisions about the production of goods, and incorporates social and temporal traps, allowing a variety of strategies to be used. The students who participated in our simulation expressed greater confidence in their knowledge about climate change, social dilemmas, social traps, temporal traps, decisionmaking strategies in social dilemmas, the effects on the climate of overconsumption, the effects on the environment of overpopulation, the reasons for environmental problems, and sustainability strategies. This is important because it suggests that the simulation creates an engaging educational experience while also boosting the students' confidence in their knowledge about social dilemmas and environmental challenges. We did not assess the accuracy of the student learning directly, as knowledge about climate change has not been found to motivate climate action $[10,69]$, but we found that the participants' beliefs about their understanding were affected by their experience.

As predicted, environmental concern was higher for the simulation group, but the within-subjects tests indicated that the simulation group — as well as the environmental studies with no simulation group-did not change from pre- to post-test, whereas the control condition dropped in concern. It is not possible to determine if this decrease was statistically spurious or caused by some outside factor related to the content of the nonenvironmental course material, and so we recommend that future researchers explore the conditions under which participating in a climate-specific social dilemma simulation may influence people's concern for the environment. Additionally, we have initial evidence that the students who participated in the simulation may also have reported stronger belief in global warming than those who did not participate in the simulation, but more research is needed to replicate this effect, as it was inconsistent across the analyses. These results highlight a potentially important avenue for future research, because people's 
climate-related beliefs and feelings are consistent predictors of their willingness to act in a climate-protective manner and support climate-friendly policies [86]. In the United States, where this study was conducted, climate beliefs are deeply politically ingrained and largely influenced by the social groups people belong to and the political landscape they inhabit [86-88]. Consequently, it can be difficult to positively influence these beliefs without activating political identities. When people are resistant to climate-protective initiatives because of political identities, otherwise-constructive climate-protective policies and projects can be derailed or cancelled [89]. If participating in a social dilemma simulation could activate climate beliefs while also side-stepping political concerns, then it could be an important teaching tool with the ability to positively impact how a person thinks and feels about climate change.

Importantly, and as predicted, we also found that the motivation to act in a climatefriendly manner was higher for the participants who completed the simulation compared to those who did not, as well as being higher among the simulation participants postsimulation compared to their pre-simulation levels. This was consistent for three of the four types of motivation we examined: identified, integrated and intrinsic motivation. No significant effects were found for introjected motivation. These findings are important because they suggest that our simulation may be effective as a potential behavioral intervention, which could have lasting effects on the participants' willingness to engage with climate-protective actions. Identified, integrated and intrinsic motivation are closely linked to the performance of pro-environmental behaviors [90]. By activating these types of motivation via the simulation, the participants came away feeling that pro-climate behavior is consistent with their personal goals (identified motivation), part of their personal identities (integrated motivation), and that it feels good to do (intrinsic motivation) [78,79]. People who express stronger identified, integrated and intrinsic motivation are more likely to perform pro-environmental actions than people with relatively weak motivations. Moreover, compared to more extrinsic forms of motivation (like introjected motivation), intrinsic forms of motivation may be more likely to boost pro-environmental behaviors for a longer duration and across a variety of situations [91].

Critically, in addition to influencing strong behavioral antecedents, we also found evidence that our simulation may increase the likelihood of performing actual climateprotective behaviors. Specifically, and as predicted, the participants who completed the simulation were more likely to perform both personal and social behaviors, like donating money or time and signing petitions to support climate-friendly initiatives. The satisfactory reliability of our behavior index, in addition to observing a consistent pattern of results for volunteering behaviors, suggests that the influence of our simulation may be generalizable across multiple pro-climate behaviors. This is important both theoretically and practically, as it suggests that the underlying psychological mechanisms through which our simulation influences behavior are unlikely to change depending on what behavior is being targeted. Although we cannot be certain how environmentally significant these behaviors would be from an impact perspective, Stern [80] argues that these types of public-sphere behaviors can be powerful through their influence on policies. The examination of these types of behaviors is important because they offer people ways to bridge the individual and the collective in a way that can also be personally rewarding (e.g., volunteering) [92]. In order to adequately mitigate and adapt to global warming, changes at all levels of the system will be required, and so it is vital that behavioral scientists study both actions at the individual level and at those that help individuals connect to the larger collective effort.

Altogether, these findings are both theoretically and practically important. From a theoretical perspective, we explored a critical gap in the literature which had not been previously addressed. Specifically, we expanded the scope of social dilemma simulations beyond what occurs during the game to explore how participating in these types of simulations may impact the participants' thoughts, feelings and actions after the simulation has ended. From a practical perspective, our findings suggest that climate change-specific social dilemma simulations might offer an engaging, educational and potentially psychologically 
powerful tool for the promotion of both the understanding of climate-relevant behaviors and the motivation to act in a climate-friendly manner. The participants may recognize both their own personal responsibilities and the need to collectively change the social structures that constrain decisions and create climate traps. When it comes to teaching, our results support the notion that including a learning module consisting of the Climate Trap simulation, along with the discussion of social dilemmas in the context of climate change and human solutions, may be an effective teaching intervention in many different kinds of sustainability studies courses. Our simulation may help strengthen learning, reinforcing links to many important issues in trying to understand why people, even those who are aware of the threat of climate change, still may not act in a climate-protective manner. In addition, many courses or other environmental education activities have a goal to motivate the participants to act on their knowledge, and the simulation was able to do so.

In addition to those discussed above, our results shed light on many potentially fruitful avenues for future research related to the underlying psychological drivers of the observed effects. Specifically, while we do have initial evidence that participating in a climate-specific social dilemma simulation can be both educational and motivating to act in a climate-friendly manner, the precise psychological process through which these types of simulations influence actions is yet unknown. We did not explicitly test a particular theory of change; however, ours is essentially a motivational model, grounded primarily in Protection Motivation Theory [51-53]. That said, what pushed the motivation into the more self-directed forms is not clear. The simulation may have been effective for any number of reasons, and the extant literature gives some hints as to what may be underlying the changes we observed. For example, Krasny [8] reviewed 10 intermediate outcomes in environmental education that mediate between an activity and a behavioral outcome: (1) knowledge and thinking; (2) values, beliefs, and attitudes; (3) nature connectedness; (4) a sense of place; (5) efficacy; (6) identity; (7) norms; (8) social capital; (9) positive youth development; and (10) health and wellbeing. We suggest that our participants likely acted pro-environmentally in response to our simulation as a result of more internal factors, rather than any structural or social ones that were inherent in the activity. We suspect that the simulation woke the participants up to the understanding that the necessary change to address global warming is constrained by social dilemma pressures, which is potentially a form of systems knowledge [93]. This realization may have helped them see that the threat is serious, not just because of the physical changes to the environment, but because the current structures in society—-such as economic systems and regulationsdo not readily reward climate-protective decisions in many domains, especially in the corporate production of consumer goods. When they observed themselves being vulnerable to the same pressures in the simulation, the participants may have been motivated to overcome the trap, as is consistent with Capstick's finding that " ... among the participants' perspectives, strong arguments can also be found for action in spite of - even because of the social dilemma nature of climate change" (35, p. 3495). In Protection Motivation Theory terminology, we speculate that the simulation activated people's perceptions of climate change as a severe threat (severity), with negative potential impacts for them (vulnerability), that is also influenced by their behaviors (response efficacy), and so they are efficacious enough to help prevent it (self-efficacy). By creating a situation in which the participants view the situational influence of social dilemmas and climate change through these lenses, we may have created an experience powerful enough to motivate action. Future studies need to test whether the underlying psychological processes align with Protection Motivation Theory, or if alternative influences are at play, [8].

Moreover, our results suggest that there are 'post-game' consequences to participating in social dilemma simulations, and future research could explore the psychological process through which post-game thoughts, feelings, motivations and emotions influence postgame actions. Unfortunately, we could not run mediational analyses using the variables of confidence in knowledge, environmental concern, global warming belief, and motivation to predict action because we were only able to give the behavior options to a subset of the 
participants who did not report on the other questions. This would be an important theoretical next step for this research to better our understanding of the downstream psychological consequences that the participation in simulations has for the participants' behaviors.

Besides determining the underlying causes of the changes we observed, it is important to understand the conditions under which the effect of the climate-specific social dilemma simulation on climate-friendly thoughts, feelings and actions may be stronger or weaker (i.e., to assess generalizability). At this point, we cannot conclude whether it is the climatespecific nature of our simulation which is driving the observed effects, or if it is more about the dynamics and experience of social dilemmas generally. In addition, further exploration is needed to determine whether the effect of the simulation would be the same for everyone and at all times. For example, as the public becomes more aware of the adverse effects of climate change [94], or in cases in which their climate beliefs are more salient because of a recent weather event or season, or because it is the subject of an important political election primary process [86,87], the simulation may be an even more potent catalyst for change, especially in how it illuminates the links between the production of consumer goods and climate change. This could help people to understand their own responsibility in causing and addressing global warming. In addition, further testing could determine whether the findings are generalizable beyond college student participants. The use of the simulation with the general public, as well as policy-makers and corporate leaders, could stimulate change beyond the individual level, as these people often wield institutional power. Finally, it will be important to determine whether the simulation can affect behaviors when the participants are not specifically offered behavioral options, and whether the simulation can lead to other kinds of changes, such as lifestyle behaviors. We have reason for optimism, given that our participants' motivation became more self-directed, which prior research has found can produce more and longer-lasting environmentally-supportive action [72].

Lastly, it is common for educational simulations in other domains to be evaluated as we have here (i.e., for impacts on the participants post-simulation) $[95,96]$, and it would be advantageous to expand this approach to other environmental simulations. In particular, the other climate-change-related simulations that have been developed, including ones focused on a social dilemma, could be tested in this way. Milinski and colleagues [58] and Tavoni et al. [59] found that the participants were not inclined to invest in an account representing the climate when doing so meant that they would be sacrificing money in their own account. Although these simulations likely did not spur high cognitive involvement because they were not as veridical to real life decision-making [62], participation may nevertheless lead to significant changes in the participants afterwards. Conversely, the Climate Trap simulation may be used in the same way as prior social dilemma simulations, that is, to determine the factors that predict behavior within the simulation. As a more complex simulation explicitly tied to climate change, and one which includes innovations such as the nonlinear change of the climate, research can determine whether the variables that have previously been found to matter in social dilemmas, including communication among the participants, regulations, penalties and norms, etc. [24], operate the same way with respect to climate change.

It is worth noting that although the simulation was found to be effective and could have many uses, a downside is that-in its current form-it is time-consuming and cognitively-demanding to run for the facilitator, who has to shuttle back and forth between the rooms and keep track of the pairings. This fact resulted in the capacity to run only small batches of participants at a time in each session. A computer application to run the simulation through a website that manages the calculations and anonymous groupings, and which allows for more people in a "marketplace" than pairs, is currently in phase two of development, and will be available from the first author.

\section{Conclusions}

As the mitigation of climate change becomes increasingly urgent, many activists, teachers and others who create educational programs must design them with strong and 
reliable antecedents of climate action in mind. Our Climate Trap: Social Dilemma Simulation is specifically focused on giving the participants a close-up view of how they themselves make behavioral decisions under social dilemma pressures related to climate change, and was an effective activity. It increased the participants' confidence in their knowledge of the social dilemma context of climate change, environmental concern and self-determined motivations to act, and ultimately led to actual climate-protective behavior. Ultimately, social dilemma pressures are baked into how our social, political and corporate worlds are arranged. Helping people to recognize the way in which institutions and powerful entities set up constraints that then lead to the many tradeoffs that are often decided in ways that harm the climate and environment may result in demands to change them.

The research on our climate change social dilemma simulation is situated in the myriad literature on the psychological, and specifically the social psychological factors, that produce pro-environmental behavior [14,97-103]. We hope that research using our Climate Trap: Social Dilemma Simulation can make additional contributions to understanding the factors that promote climate-protective behavior. Overall, our findings support the notion that climate-specific social dilemma simulations can be fruitfully implemented as both teaching and learning tools, and as interventions which promote climate-protective behaviors. This, and perhaps similar simulations, may offer educators the opportunity to teach about the human dimensions of climate change in a way that benefits both their students and the environment.

Author Contributions: P.B.D. was responsible for the conceptualization of the simulation, funding acquisition, project administration, and writing of the original draft. S.J.Z. was responsible for visualization and review and editing of the original draft. Both authors were responsible for methodology, data curation, formal analysis, investigation, and resources. Both authors have read and agreed to the published version of the manuscript.

Funding: This research was funded by three Research Grants from York College of Pennsylvania. The research conformed to the guidelines of the APA ethics and is in accordance with the Declaration of Helsinki. The protocol was approved by the IRB of York College of Pennsylvania with the ID F13BS0.

Informed Consent Statement: Informed consent was obtained from all subjects involved in the study.

Data Availability Statement: Data for this study and the web-based application to run the simulation, funded by York College of Pennsylvania and the Society for the Psychological Study of Social Issues (SPSSI), will be available by contacting the first author at pdruen@ycp.edu.

Acknowledgments: The authors would like to thank Kevin Arps for his feedback on prior drafts of this paper, Keith Peterman and Trish McGee who allowed their students to participate in this research, Michelle Yoder who consulted on the use of simulations, and Neil Leary who organized a NASA-sponsored workshop at Dickinson College and Andy Skelton, who attended that workshop, for discussion during which the inspiration for the social dilemma simulation arose.

Conflicts of Interest: The authors declare no conflict of interest. The funders had no role in the design of the study; in the collection, analyses, or interpretation of data; in the writing of the manuscript, or in the decision to publish the results. 


\section{Appendix A}

\section{COMPANY WORTH CHANGE MATRIX}

The numbers in the cells indicate your profit percentage (in red) and the other company's profit percentage (in blue). The percentage is multiplied by the Resource Worth (which may change each round) and then added to your prior company worth.

\begin{tabular}{|c|c|c|c|c|c|c|c|c|c|c|c|c|c|c|}
\hline & -15 & & -10 & & -5 & & 0 & & 5 & & 10 & & 15 & \\
\hline \multirow[t]{2}{*}{-15} & & 6 & & 7 & & 8 & & 9 & & 10 & & 11 & & 12 \\
\hline & 6 & & 4 & & 2 & & 0 & & -2 & & -4 & & -6 & \\
\hline \multirow[t]{2}{*}{-10} & & 4 & & 5 & & 6 & & 7 & & 8 & & 9 & & 10 \\
\hline & 7 & & 5 & & 3 & & 1 & & -1 & & -3 & & -5 & \\
\hline \multirow[t]{2}{*}{-5} & & 2 & & 3 & & 4 & & 5 & & 6 & & 7 & & 8 \\
\hline & 8 & & 6 & & 4 & & 2 & & 0 & & -2 & & -4 & \\
\hline \multirow[t]{2}{*}{0} & & 0 & & 1 & & 2 & & 3 & & 4 & & 5 & & 6 \\
\hline & 9 & & 7 & & 5 & & 3 & & 1 & & -1 & & -3 & \\
\hline \multirow[t]{2}{*}{5} & & -2 & & -1 & & 0 & & 1 & & 2 & & 3 & & 4 \\
\hline & 10 & & 8 & & 6 & & 4 & & 2 & & 0 & & -2 & \\
\hline \multirow[t]{2}{*}{10} & & -4 & & -3 & & -2 & & -1 & & 0 & & 1 & & 2 \\
\hline & 11 & & 9 & & 7 & & 5 & & 3 & & 1 & & 0 & \\
\hline \multirow[t]{2}{*}{15} & & -6 & & -5 & & -4 & & -3 & & -2 & & -1 & & 0 \\
\hline & 12 & & 10 & & 8 & & 6 & & 4 & & 2 & & 0 & \\
\hline
\end{tabular}

\section{RESOURCE WORTH CHANGE MATRIX}

\begin{tabular}{|l|l|l|l|l|l|l|l|}
\hline & -15 & -10 & -5 & 0 & 5 & 10 & 15 \\
\hline-15 & $60 \%$ & $50 \%$ & $40 \%$ & $30 \%$ & $20 \%$ & $10 \%$ & $0 \%$ \\
\hline-10 & $50 \%$ & $40 \%$ & $30 \%$ & $20 \%$ & $10 \%$ & $0 \%$ & $-10 \%$ \\
\hline-5 & $40 \%$ & $30 \%$ & $20 \%$ & $10 \%$ & $0 \%$ & $-10 \%$ & $-20 \%$ \\
\hline 0 & $30 \%$ & $20 \%$ & $10 \%$ & $0 \%$ & $-10 \%$ & $-20 \%$ & $-30 \%$ \\
\hline 5 & $20 \%$ & $10 \%$ & $0 \%$ & $-10 \%$ & $-20 \%$ & $-30 \%$ & $-40 \%$ \\
\hline 10 & $10 \%$ & $0 \%$ & $-10 \%$ & $-20 \%$ & $-30 \%$ & $-40 \%$ & $-50 \%$ \\
\hline 15 & $0 \%$ & $-10 \%$ & $-20 \%$ & $-30 \%$ & $-40 \%$ & $-50 \%$ & $-60 \%$ \\
\hline
\end{tabular}

Figure A1. Matrices used in running the simulation to show how the company's worth would change and to show how the resource would change as a joint outcome of both players' decisions.

\section{References}

1. Perlaviciute, G.; Steg, L.; Sovacool, B.K. A perspective on the human dimensions of a transition to net-zero energy systems. Energy Clim. Chang. 2021, 2, 100042. [CrossRef]

2. Swim, J.K.; Clayton, S.; Doherty, T.; Gifford, R.; Howard, G.; Reser, J.; Stern, P.; Weber, E. Psychology and Global Climate Change: Addressing a Multifaceted Problem and Set of Challenges; American Psychological Association: Washington, DC, USA, 2010. Available online: http:/ / www.apa.org/science/about/publications/climate-change.aspx (accessed on 22 June 2021).

3. Weber, E.U. Climate change demands behavioral change: What are the challenges? Soc. Res. 2015, 82, 561-581. 
4. Dietz, T.; Gardner, G.T.; Gilligan, J.; Stern, P.C.; Vandenbergh, M.P. Household actions can provide a behavioral wedge to rapidly reduce US carbon emissions. Proc. Natl. Acad. Sci. USA 2009, 106, 18452-18456. [CrossRef]

5. Monthly Energy Review; Office of Energy Statistics: Washington, DC, USA, 2021; pp. 1-272.

6. Anderson, A. Climate Change Education for Mitigation and Adaptation. J. Educ. Sustain. Dev. 2013, 6, 191-206. [CrossRef]

7. Mochizuki, Y.; Bryan, A. Climate Change Education in the Context of Education for Sustainable Development: Rationale and Principles. J. Educ. Sustain. Dev. 2015, 9, 4-26. [CrossRef]

8. Krasny, M.E. Advancing Environmental Education Practice; Comstock Publishing Associates: Ithaca, NY, USA, 2020.

9. Zelezny, L.C. Educational Interventions That Improve Environmental Behaviors: A Meta-Analysis. J. Environ. Educ. 1999, 31, 5-14. [CrossRef]

10. Abrahamse, W.; Steg, L.; Vlek, C.; Rothengatter, T. A review of intervention studies aimed at household energy conservation. J. Environ. Psychol. 2005, 25, 273-291. [CrossRef]

11. Nisa, C.F.; Bélanger, J.; Schumpe, B.M.; Faller, D.G. Meta-analysis of randomised controlled trials testing behavioural interventions to promote household action on climate change. Nat. Commun. 2019, 10, 4545. [CrossRef]

12. Ruepert, A.M.; Keizer, K.; Steg, L. The relationship between Corporate Environmental Responsibility, employees' biospheric values and pro-environmental behaviour at work. J. Environ. Psychol. 2017, 54, 65-78. [CrossRef]

13. Shwom, R.; Isenhour, C.; Jordan, R.C.; McCright, A.M.; Robinson, J.M. Integrating the social sciences to enhance climate literacy. Front. Ecol. Environ. 2017, 15, 377-384. [CrossRef]

14. Swim, J.K.; Clayton, S.; Howard, G.S. Human behavioral contributions to climate change: Psychological and contextual drivers. Am. Psychol. 2011, 66, 251-264. [CrossRef] [PubMed]

15. Thøgersen, J. Consumer behavior and climate change: Consumers need considerable assistance. Curr. Opin. Behav. Sci. 2021, 42, 9-14. [CrossRef]

16. Venhoeven, L.A.; Bolderdijk, J.W.; Steg, L. Why going green feels good. J. Environ. Psychol. 2020, 71, 101492. [CrossRef]

17. Zawadzki, S.J.; Steg, L.; Bouman, T. Meta-analytic evidence for a robust and positive association between individuals' proenvironmental behaviors and their subjective wellbeing. Environ. Res. Lett. 2020, 15, 123007. [CrossRef]

18. Williamson, K.; Satre-Meloy, A.; Velasco, K.; Green, K. Climate Change Needs Behavior Change: Making the Case for Behavioral Solutions to Reduce Global Warming; Rare: Arlington, TX, USA, 2018. Available online: https://rare.org/wp-content/uploads/20 19/02/2018-CCNBC-Report.pdf (accessed on 1 July 2021).

19. Poortinga, W.; Steg, L.; Vlek, C. Values, Environmental Concern, and Environmental Behavior. Environ. Behav. 2004, 36, 70-93. [CrossRef]

20. Jamieson, D. Climate Change, Responsibility, and Justice. Sci. Eng. Ethic 2009, 16, 431-445. [CrossRef]

21. Brick, C.; Bosshard, A.; Whitmarsh, L. Motivation and climate change: A review. Curr. Opin. Psychol. 2021, 42, 82-88. [CrossRef]

22. Spence, A.; Poortinga, W.; Butler, C.; Pidgeon, N.F. Perceptions of climate change and willingness to save energy related to flood experience. Nat. Clim. Chang. 2011, 1, 46-49. [CrossRef]

23. Dawes, R.M. Social Dilemmas. Annu. Rev. Psychol. 1980, 31, 169-193. [CrossRef]

24. Gifford, R. Toward a Comprehensive Model of Social Dilemmas. In New Issues and Paradigms in Research on Social Dilemmas; Springer Science and Business Media LLC: Berlin, Germany, 2008; pp. 265-279.

25. Huckelba, A.L.; Lange PA, M.V. The silent killer: Consequences of climate change and how to survive past the year 2050. Sustainability 2020, 12, 3757. [CrossRef]

26. Mann, M.E. The New Climate War: The Fight to Take Back Our Planet. In Public Affairs Books; PublicAffairs: New York, NY, USA, 2021.

27. Supran, G.; Oreskes, N. Rhetoric and frame analysis of ExxonMobil's climate change communications. One Earth 2021, 4, 696-719. [CrossRef]

28. Nisbett, R.E.; Schachter, S. Cognitive manipulation of pain. J. Exp. Soc. Psychol. 1966, 2, 227-236. [CrossRef]

29. Pidgeon, N. Public understanding of, and attitudes to, climate change: UK and international perspectives and policy. Clim. Policy 2012, 12, S85-S106. [CrossRef]

30. Wells, V.K.; Ponting, C.A.; Peattie, K. Behaviour and climate change: Consumer perceptions of responsibility. J. Mark. Manag. 2011, 27, 808-833. [CrossRef]

31. Truelove, H.B.; Parks, C. Perceptions of behaviors that cause and mitigate global warming and intentions to perform these behaviors. J. Environ. Psychol. 2012, 32, 246-259. [CrossRef]

32. Joireman, J. Environmental problems as social dilemmas: The temporal dimension. In Understanding Behavior in the Context of Time: Theory, Research, and Application; Strathman, A., Joireman, J., Eds.; Lawrence Erlbaum Associates Publishers: Mahwah, NJ, USA, 2005; pp. 289-304.

33. Lazarus, R. Super wicked problems and climate change: Restraining the present to liberate the future. Cornell Law Rev. 2008, 94, 1153-1234.

34. Levin, K.; Cashore, B.; Bernstein, S.; Auld, G. Playing it forward: Path dependency, progressive incrementalism, and the "super wicked" problem of global climate change. In Proceedings of the IOP Conference Series: Earth and Environmental Science, 6, Proceedings of the Climate Change: Global Risks, Challenges and Decisions Congress, Copenhagen, Denmark, 10-12 March 2009.

35. Capstick, S.B. Public Understanding of Climate Change as a Social Dilemma. Sustainability 2013, 5, 3484-3501. [CrossRef]

36. Hasson, R.; Löfgren, A.; Visser, M. Climate change in a public goods game: Investment decision in mitigation versus adaptation. Ecol. Econ. 2010, 70, 331-338. [CrossRef] 
37. Kollock, P. Social Dilemmas: The Anatomy of Cooperation. Annu. Rev. Sociol. 1998, 24, 183-214. [CrossRef]

38. Nordhaus, W.D. Reflections on the Economics of Climate Change. J. Econ. Perspect. 1993, 7, 11-25. [CrossRef]

39. Van Dijk, E.; De Dreu, C.K. Experimental Games and Social Decision Making. Annu. Rev. Psychol. 2021, 72, 415-428. [CrossRef]

40. Raihani, N.; Aitken, D. Uncertainty, rationality and cooperation in the context of climate change. Clim. Chang. 2011, 108, 47-55. [CrossRef]

41. Osbaldiston, R.; Sheldon, K.M. Social dilemmas and sustainability: Promoting people's motivation to "cooperate with the future". In Psychology of Sustainable Development; Schmuck, P., Schultz, W.P., Eds.; Klewer Academic Publishers: Boston, MA, USA, 2002.

42. Hilbig, B.E.; Zettler, I.; Moshagen, M.; Heydasch, T. Tracing the Path from Personality-Via Cooperativeness-To Conservation. Eur. J. Pers. 2013, 27, 319-327. [CrossRef]

43. Stanley, S.K.; Hogg, T.L.; Leviston, Z.; Walker, I. From anger to action: Differential impacts of eco-anxiety, eco-depression, and eco-anger on climate action and wellbeing. J. Clim. Chang. Health 2021, 1, 100003. [CrossRef]

44. Schmitt, M.T.; Aknin, L.B.; Axsen, J.; Shwom, R.L. Unpacking the Relationships Between Pro-environmental Behavior, Life Satisfaction, and Perceived Ecological Threat. Ecol. Econ. 2018, 143, 130-140. [CrossRef]

45. Curtin, J.; McInerney, C.; Johannsdottir, L. How can financial incentives promote local ownership of onshore wind and solar projects? Case study evidence from Germany, Denmark, the UK and Ontario. Local Econ. J. Local Econ. Policy Unit 2018, 33, 40-62. [CrossRef]

46. Kopelman, S.; Weber, J.M.; Messick, D.M. Factors influencing cooperation in commons dilemmas: A review of experimental psychological research. In The Drama of the Commons; Ostrom, E., Dietz, T., Dolšak, N., Stern, P.C., Stonich, S., Weber, E.U., Eds.; National Academies Press: Washington, DC, USA, 2002; pp. 113-156.

47. Van Lange, P.A.; Joireman, J.; Parks, C.; Van Dijk, E. The psychology of social dilemmas: A review. Organ. Behav. Hum. Decis. Process. 2013, 120, 125-141. [CrossRef]

48. Aitken, C.; Chapman, R.; McClure, J. Climate change, powerlessness and the commons dilemma: Assessing New Zealanders' preparedness to act. Glob. Environ. Chang. 2011, 21, 752-760. [CrossRef]

49. Clark, K.; Sefton, M. The Sequential Prisoner's Dilemma: Evidence on Reciprocation. Econ. J. 2001, 111, 51-68. [CrossRef]

50. Vasi, I.B.; Macy, M. The Mobilizer's Dilemma: Crisis, Empowerment, and Collective Action. Soc. Forces 2003, 81, 979-998. [CrossRef]

51. Rogers, R.W. A protection motivation theory of fear appeals and attitude change. J. Psychol. 1975, 91, 93-114. [CrossRef] [PubMed]

52. Rogers, R. Cognitive and physiological processes in fear-based attitude change: A revised theory of protection motivation. In Social Psychophysiology: A Sourcebook; Caccioppo, J., Petty, R., Eds.; Guilford: New York, NY, USA, 1983; pp. $153-176$.

53. Cismaru, M.; Cismaru, R.; Ono, T.; Nelson, K.Y. "Act on Climate Change": An Application of Protection Motivation Theory. Soc. Mark. Q. 2011, 17, 62-84. [CrossRef]

54. Abraham, B. Video game visions of climate futures: ARMA 3 and implications for games and persuasion. Games Cult. 2018, 13, 71-91. [CrossRef]

55. Besalti, M. Games for CHANGE: High School Students' Learning Experiences and Motivation to Learn Climate Change Science through Educational Computer Games. Ph.D. Thesis, University of South Florida, Tampa, FL, USA, 2019.

56. Crookall, D. Climate Change and Simulation/Gaming. Simul. Gaming 2013, 44, 195-228. [CrossRef]

57. Eisenack, K.; Reckien, D. Climate Change and Simulation/Gaming. Simul. Gaming 2013, 44, 245-252. [CrossRef]

58. Milinski, M.; Sommerfeld, R.D.; Krambeck, H.-J.; Reed, F.; Marotzke, J. The collective-risk social dilemma and the prevention of simulated dangerous climate change. Proc. Natl. Acad. Sci. USA 2008, 105, 2291-2294. [CrossRef]

59. Tavoni, A.; Dannenberg, A.; Kallis, G.; Löschel, A. Inequality, communication, and the avoidance of disastrous climate change in a public goods game. Proc. Natl. Acad. Sci. USA 2011, 108, 11825-11829. [CrossRef]

60. Brehm, S.S.; Brehm, J.W. Psychological Reactance: A Theory of Freedom and Control; Academic Press: Cambridge, MA, USA, 2013.

61. Schwartz, S. An Overview of the Schwartz Theory of Basic Values. Online Read. Psychol. Cult. 2012, 2, 1. [CrossRef]

62. Williams, A.; Williams, R.H. Red light, green light: Altering attitudes about climate change with a game prac-ticesimulation game. Psicol. Política 2008, 37, 71-84.

63. Johnson, S.L.; Druen, P.B. A Climate Change-Specific Social Dilemma Game: Systematically Varying Rule-Sets. In Proceedings of the Meeting of the Society for the Psychological Study of Social Issues (SPSSI), Charlotte, NC, USA, 24-26 June 2012.

64. Wachholz, S.; Artz, N.; Chene, D. Warming to the idea: University students' knowledge and attitudes about climate change. Int. J. Sustain. High. Educ. 2014, 15, 128-141. [CrossRef]

65. Dickinson, J.L.; Crain, R.; Yalowitz, S.; Cherry, T.M. How Framing Climate Change Influences Citizen Scientists' Intentions to Do Something About It. J. Environ. Educ. 2013, 44, 145-158. [CrossRef]

66. Feinberg, M.; Willer, R. Apocalypse Soon? Psychol. Sci. 2011, 22, 34-38. [CrossRef] [PubMed]

67. Wolfe, S.E.; Tubi, A. Terror Management Theory and mortality awareness: A missing link in climate response studies? Wiley Interdiscip. Rev. Clim. Chang. 2019, 10, e566. [CrossRef]

68. Bouman, T.; Verschoor, M.; Albers, C.; Böhm, G.; Fisher, S.D.; Poortinga, W.; Whitmarsh, L.; Steg, L. When worry about climate change leads to climate action: How values, worry and personal responsibility relate to various climate actions. Glob. Environ. Chang. 2020, 62, 102061. [CrossRef] 
69. Platt, R.; Retallack, S. Consumer Power: How the Public Thinks Lower-Carbon Behaviour Could Be Made Mainstream; Institute for Public Policy Research: London, UK, 2009. Available online: https://www.ippr.org/files/images/media/files/publication/2011/05/ consumer_power_1723.pdf (accessed on 1 July 2021).

70. Bord, R.J.; O'Connor, R.E.; Fisher, A. In what sense does the public need to understand global climate change? Public Underst. Sci. 2000, 9, 205-218. [CrossRef]

71. Haller, M.; Hadler, M. Dispositions to Act in Favor of the Environment: Fatalism and Readiness to Make Sacrifices in a Cross-National Perspective. Sociol. Forum 2008, 23, 281-311. [CrossRef]

72. Baxter, D.; Pelletier, L.G. The roles of motivation and goals on sustainable behaviour in a resource dilemma: A self-determination theory perspective. J. Environ. Psychol. 2020, 69, 101437. [CrossRef]

73. Sheldon, K.M.; McGregor, H.A. Extrinsic Value Orientation and "The Tragedy of the Commons". J. Pers. 2000, 68, 383-411. [CrossRef]

74. Darner, R. An empirical test of self-determination theory as a guide to fostering environmental motivation. Environ. Educ. Res. 2012, 18, 463-472. [CrossRef]

75. Ellis, R.J.; Thompson, F. Culture and the Environment in the Pacific Northwest. Am. Political Sci. Rev. 1997, 91, 885-897. [CrossRef]

76. Dutcher, D.D.; Finley, J.C.; Luloff, A.; Johnson, J.B. Connectivity with Nature as a Measure of Environmental Values. Environ. Behav. 2007, 39, 474-493. [CrossRef]

77. Pelletier, L.G.; Tuson, K.M.; Green-Demers, I.; Noels, K.; Beaton, A.M. Why Are You Doing Things for the Environment? The Motivation Toward the Environment Scale (MTES)1. J. Appl. Soc. Psychol. 1998, 28, 437-468. [CrossRef]

78. Deci, E.; Ryan, R.M. Motivation, Personality, and Development Within Embedded Social Contexts: An Overview of SelfDetermination Theory. In The Oxford Handbook of Human Motivation; Ryan, R.M., Ed.; Oxford Library of Psychology; Oxford University Press: Oxford, UK, 2012; pp. 84-107.

79. Ryan, R.M.; Deci, E.L. Self-Determination Theory: Basic Psychological Needs in Motivation, Development, and Wellness; The Guilford Press: New York, NY, USA, 2017.

80. Stern, P.C. Toward a coherent theory of environmentally significant behavior. J. Soc. Issues 2000, 56, 407-424. [CrossRef]

81. Larson, L.R.; Stedman, R.C.; Cooper, C.B.; Decker, D.J. Understanding the multi-dimensional structure of pro-environmental behavior. J. Environ. Psychol. 2015, 43, 112-124. [CrossRef]

82. Nilsson, A.; Bergquist, M.; Schultz, W.P. Spillover effects in environmental behaviors, across time and context: A review and research agenda. Environ. Educ. Res. 2017, 23, 573-589. [CrossRef]

83. Sarstedt, M.; Wilczynski, P. More for less? A comparison of single-item and multi-item measures. Die Betr. 2009, 69, $211-227$.

84. Diamantopoulos, A.; Sarstedt, M.; Fuchs, C.; Wilczynski, P.; Kaiser, S. Guidelines for choosing between multi-item and single-item scales for construct measurement: A predictive validity perspective. J. Acad. Mark. Sci. 2012, 40, 434-449. [CrossRef]

85. Crowne, D.P.; Marlowe, D. A new scale of social desirability independent of psychopathology. J. Consult. Psychol. 1960, 24, 349-354. [CrossRef]

86. Zawadzki, S.J.; Bouman, T.; Steg, L.; Bojarskich, V.; Druen, P.B. Translating climate beliefs into action in a changing political landscape. Clim. Chang. 2020, 161, 21-42. [CrossRef]

87. Hahnel, U.J.J.; Mumenthaler, C.; Brosch, T. Emotional foundations of the public climate change divide. Clim. Chang. 2019, 161, 9-19. [CrossRef]

88. Dietz, T. Political events and public views on climate change. Clim. Chang. 2020, 161, 1-8. [CrossRef] [PubMed]

89. Perlaviciute, G.; Schuitema, G.; Devine-Wright, P.; Ram, B. At the Heart of a Sustainable Energy Transition: The Public Acceptability of Energy Projects. IEEE Power Energy Mag. 2018, 16, 49-55. [CrossRef]

90. Van der Werff, E.; Steg, L.; Keizer, K. It is a moral issue: The relationship between environmental self-identity, obligation-based intrinsic motivation and pro-environmental behaviour. Glob. Environ. Chang. 2013, 23, 1258-1265. [CrossRef]

91. Van der Linden, S. Intrinsic motivation and pro-environmental behaviour. Nat. Clim. Chang. 2015, 5, 612-613. [CrossRef]

92. Janmaimool, P.; Denpaiboon, C. Evaluating determinants of rural Villagers' engagement in conservation and waste management behaviors based on integrated conceptual framework of Pro-environmental behavior. Life Sci. Soc. Policy 2016, 12, 12. [CrossRef]

93. Fremerey, C.; Bogner, F.X. Learning about Drinking Water: How Important are the Three Dimensions of Knowledge that Can Change Individual Behavior? Educ. Sci. 2014, 4, 213-228. [CrossRef]

94. Leiserowitz, A.; Maibach, E.; Rosenthal, S.; Kotcher, J.; Carman, J.; Wang, X.; Marlon, J.; Lacroix, K.; Goldberg, M. Climate Change in the American Mind. In Yale Program on Climate Change Communication; Yale University and George Mason University: New Haven, CT, USA, 2021. Available online: https:/ / climatecommunication.yale.edu/publications/climate-change-in-the-americanmind-march-2021/ (accessed on 1 July 2021).

95. Engler, J.N.; Druen, P.B.; Steck, L.W.; Ligon, M.; Jacob, S.; Arseneau, L.J. Enhancing advocacy for individuals in poverty: The role of a poverty simulation training. Psychol. Serv. 2020, 17, 110-119. [CrossRef]

96. Steck, L.W.; Engler, J.N.; Ligon, M.; Druen, P.B.; Cosgrove, E. Doing Poverty. Teach. Sociol. 2011, 39, 259-273. [CrossRef]

97. Steg, L.; Vlek, C. Encouraging pro-environmental behaviour: An integrative review and research agenda. J. Environ. Psychol. 2009, 29, 309-317. [CrossRef]

98. Geiger, J.L.; Steg, L.; van der Werff, E.; Ünal, A.B. A meta-analysis of factors related to recycling. J. Environ. Psychol. 2019, 64, 78-97. [CrossRef] 
99. Gifford, R. The dragons of inaction: Psychological barriers that limit climate change mitigation and adaptation. Am. Psychol. 2011, 66, 290-302. [CrossRef] [PubMed]

100. Steg, L.; Perlaviciute, G.; Van Der Werff, E. Understanding the human dimensions of a sustainable energy transition. Front. Psychol. 2015, 6, 805. [CrossRef] [PubMed]

101. Stern, P.C.; Dietz, T.; Abel, T.D.; Guagnano, G.; Kalof, L. A value-belief-norm theory of support for social movements: The case of environmentalism. Hum. Ecol. Rev. 1999, 6, 81-97.

102. Fielding, K.S.; Hornsey, M.J.; Swim, J.K. Developing a social psychology of climate change. Eur. J. Soc. Psychol. 2014, 44, 413-420. [CrossRef]

103. Swim, J.K.; Geiger, N.; Zawadzki, S.J. Psychology and Energy-Use Reduction Policies. Policy Insights Behav. Brain Sci. 2014, 1, 180-188. [CrossRef] 